\title{
PENGARUH ENERGI PEMADATAN DI LABORATORIUM TERHADAP PARAMETER KOMPAKSI MATERIAL CRUSHED LIMESTONE PADALARANG
}

\author{
Andrias Suhendra Nugraha ${ }^{(1)}$, Jimmy Glorius Dwi Saputra ${ }^{(2)}$ \\ (1) Mahasiswa Program Doktor Ilmu Teknik Sipil, Universitas Katolik Parahyangan \\ dan Dosen Program Studi Teknik Sipil, Universitas Kristen Maranatha \\ Email: andrias.snugraha@gmail.com \\ (2) Alumnus Program Studi S1 Teknik Sipil, Universitas Kristen Maranatha \\ Email: jimmyglorius@yahoo.com
}

\begin{abstract}
ABSTRAK
Pelaksanaan konstruksi timbunan jalan (road embankment) merupakan suatu pekerjaan yang memerlukan kajian geoteknik. Kajian geoteknik dilakukan terhadap material timbunan (fill material) yang akan digunakan pada saat tahapan pemadatan (kompaksi) di lapangan. Evaluasi terhadap hasil suatu proses kompaksi mengacu terhadap parameter kompaksi dari fill material yang telah disyaratkan oleh spesifikasi desain. Parameter kompaksi tersebut antara lain adalah kadar air optimum (optimum moisture content, $\mathrm{w}_{\mathrm{opt}}$ ) dan berat isi kering maksimum (maximum dry density, $\left.\gamma_{\text {dry max }}\right)$.

Tujuan studi ini adalah untuk menganalisis dan mengevaluasi pengaruh energi pemadatan di laboratorium terhadap parameter kompaksi material crushed limestone yang berasal dari daerah Padalarang, Jawa Barat. Terdapat 4 (empat) variasi energi pemadatan (E) yang ditinjau pada studi ini yaitu : $605 \mathrm{kN} . \mathrm{m} / \mathrm{m}^{3}$ (energi standard Proctor, E1); $1.4 \mathrm{E} 1 ; 2.2 \mathrm{E} 1$ dan $3.0 \mathrm{E} 1$. Keseluruhan uji kompaksi di laboratorium menggunakan mold dan rammer untuk standard Proctor test (ASTM D 698).

Hasil studi menunjukkan bahwa peningkatan energi pemadatan untuk kompaksi di laboratorium sebesar 3 kali energi pemadatan standard Proctor, hanya menghasilkan kenaikan $\gamma_{d r y}$ max sebesar $5 \%$ dan merubah nilai $\mathrm{w}_{\text {opt }}$ sebesar $3 \%$. Hal ini menunjukkan bahwa peningkatan energi pemadatan di laboratorium tidak terlalu berpengaruh terhadap nilai $\gamma_{d r y} \max$ maupun $\mathrm{w}_{\mathrm{opt}}$, untuk kondisi crushed limestone bergradasi buruk (poorly graded) dengan rentang ukuran butir $0.85 \mathrm{~mm}-$ $4.75 \mathrm{~mm}$.
\end{abstract}

Kata kunci:, energi pemadatan, parameter kompaksi crushed limestone

\begin{abstract}
The implementation of road embankment construction is a work that requires a geotechnical study. A geotechnical study is carried out on fill material which will be used during the compaction stage in the field. Evaluation of the results of a compacting process refers to the compacting parameters of the fill material that have been required by the design specifications. The compacting parameters include optimum water content $\left(w_{\text {opt }}\right)$ and maximum dry density $\left(\gamma_{\text {dry } \max }\right)$.

The aim of this study is to analyze and evaluate the effect of compaction energy in the laboratory on the compacting parameters of crushed limestone material originating from Padalarang, West Java. There are 4 (four) variations of compaction energy $(E)$ reviewed in this study, namely: 605 $\mathrm{kN.m} / \mathrm{m} 3$ (energy of standard Proctor, E1); 1.4 E1; $2.2 \mathrm{El}$ and $3.0 \mathrm{E1}$. All compaction tests in the laboratory use molds and rammers for the standard Proctor test (ASTM D 698).

The results of the study showed that an increase in compaction energy for compacting in the laboratory was 3 times the compaction energy of the standrad Proctor, only increase $\gamma_{\text {dry } \max }$ by $5 \%$ and changing $w_{\text {opt }}$ by $3 \%$. This shows that for poorly graded crushed limestone with grain size ranges; $0.85 \mathrm{~mm}-4.75 \mathrm{~mm}$, the increase in compaction energy for laboratory tests does not significantly affect the value of $\gamma_{\text {dry max }}$ or $w_{\text {opt }}$.
\end{abstract}

Keywords: compaction energy, compaction parameter of crushed limestone 


\section{PENDAHULUAN}

Pelaksanaan konstruksi timbunan jalan (road embankment) merupakan suatu pekerjaan yang memerlukan kajian geoteknik. Kajian geoteknik yang dilakukan diantaranya adalah kajian teknis terhadap material timbunan (fill material) yang akan digunakan pada saat tahapan pemadatan (kompaksi) di lapangan. Fill material yang digunakan pada timbunan jalan, pada umumnya adalah material tanah. Pada perkembangan saat ini, fill material dapat berupa material crushed rock /batu pecah (Choi et al, 2018) maupun rock dust / abu batu (Satyanarayana et al, 2013).

Evaluasi terhadap hasil suatu proses kompaksi mengacu terhadap parameter kompaksi dari fill material yang disyaratkan oleh spesifikasi desain. Parameter kompaksi tersebut antara lain adalah kadar air optimum (optimum moisture content, $\mathrm{w}_{\mathrm{opt}}$ ) dan berat isi kering maksimum (maximum dry density, $\gamma_{d r y} \max$ ). Kedua parameter tersebut dapat diperoleh dari hasil uji kompaksi di laboratorium. Pada kasus di mana kekuatan tanah (strength of soil) yang lebih tinggi diperlukan, maka energi pemadatan perlu ditingkatkan pula (Gurtug dan Shridaran, 2015).

Pada studi ini akan dilakukan evaluasi perubahan parameter kompaksi dari crushed limestone sebagai fill material terhadap besaran energi kompaksi yang berbedabeda. Limestone adalah jenis batuan sedimen (sedimentary rock) yang didominasi oleh mineral calcite (Waltham, 2009). Material crushed limestone yang digunakan pada studi ini berasal dari daerah Padalarang, Jawa Barat.

\section{TUJUAN}

Tujuan studi ini adalah untuk menganalisis dan mengevaluasi pengaruh energi pemadatan di laboratorium terhadap parameter kompaksi pada material crushed limestone Padalarang.

\section{METODOLOGI}

Pengujian terhadap material crushed limestone dilakukan di Laboratorium Mekanika Tanah - Program Studi Teknik Sipil, Universitas Kristen Maranatha, Bandung. Metoda untuk setiap uji antara lain adalah :

- Uji kadar air (water content, w) di laboratorium mengacu pada standar uji ASTM D 2216.

- Uji specific gravity, $\mathrm{G}_{\mathrm{s}}$ di laboratorium mengacu pada standar uji XP CEN ISO/TS 17892-3. 
- Uji sieve analysis di laboratorium mengacu pada standar uji : BS 1377, ASTM C 136 dan ASTM D 2487.

- Uji kompaksi di laboratorium menggunakan mold (cetakan) dan rammer (penumbuk) standard Proctor dan mengacu pada standar uji ASTM D 698.

\subsection{Material Uji}

Material limestone yang digunakan sebagai sampel uji pada studi ini berasal dari salah satu quarry di Padalarang, Kabupaten Bandung Barat, Jawa Barat. Ukuran butir awal dari material tersebut adalah berupa boulder seperti tampak pada Gambar 1.

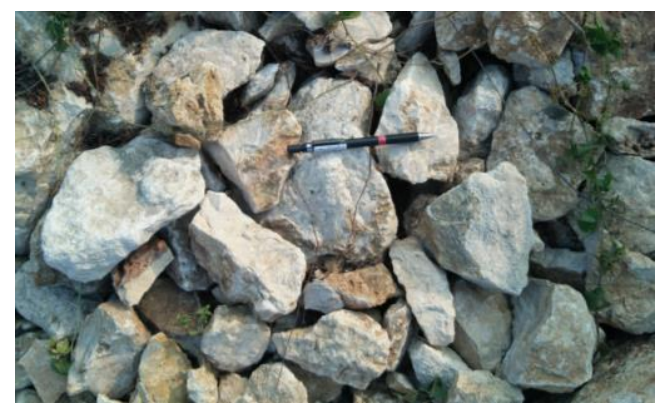

\section{Gambar 1. Limestone berukuran Boulder (Ukuran butir > 300mm)}

Untuk mendapatkan ukuran butir yang akan digunakan sebagai sampel uji, pada material limestone berukuran boulder tersebut diberlakukan proses crushing, yaitu proses penghancuran dengan menggunakan mesin crusher di salah satu pabrik di kawasan Padalarang. Mesin crusher yang digunakan tampak pada Gambar 2.

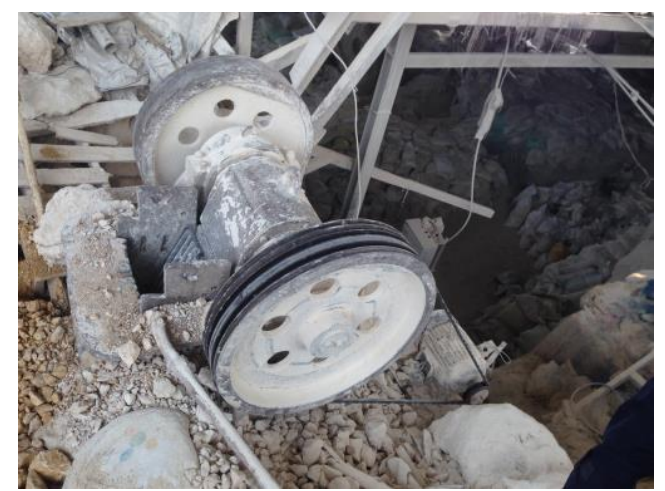

\section{Gambar 2. Mesin crusher}

Proses crushing dimulai dengan tahap penghancuran material limestone berukuran boulder dengan menggunakan mesin crusher hingga diakhiri proses tapis 
dengan saringan yang tersusun dimulai dari $4 \mathrm{~mm}, 3 \mathrm{~mm}, 2 \mathrm{~mm}$, dan $1 \mathrm{~mm}$ (Nugraha et al, 2017). Mekanisme proses cruhing tersebut tampak pada Gambar 3,

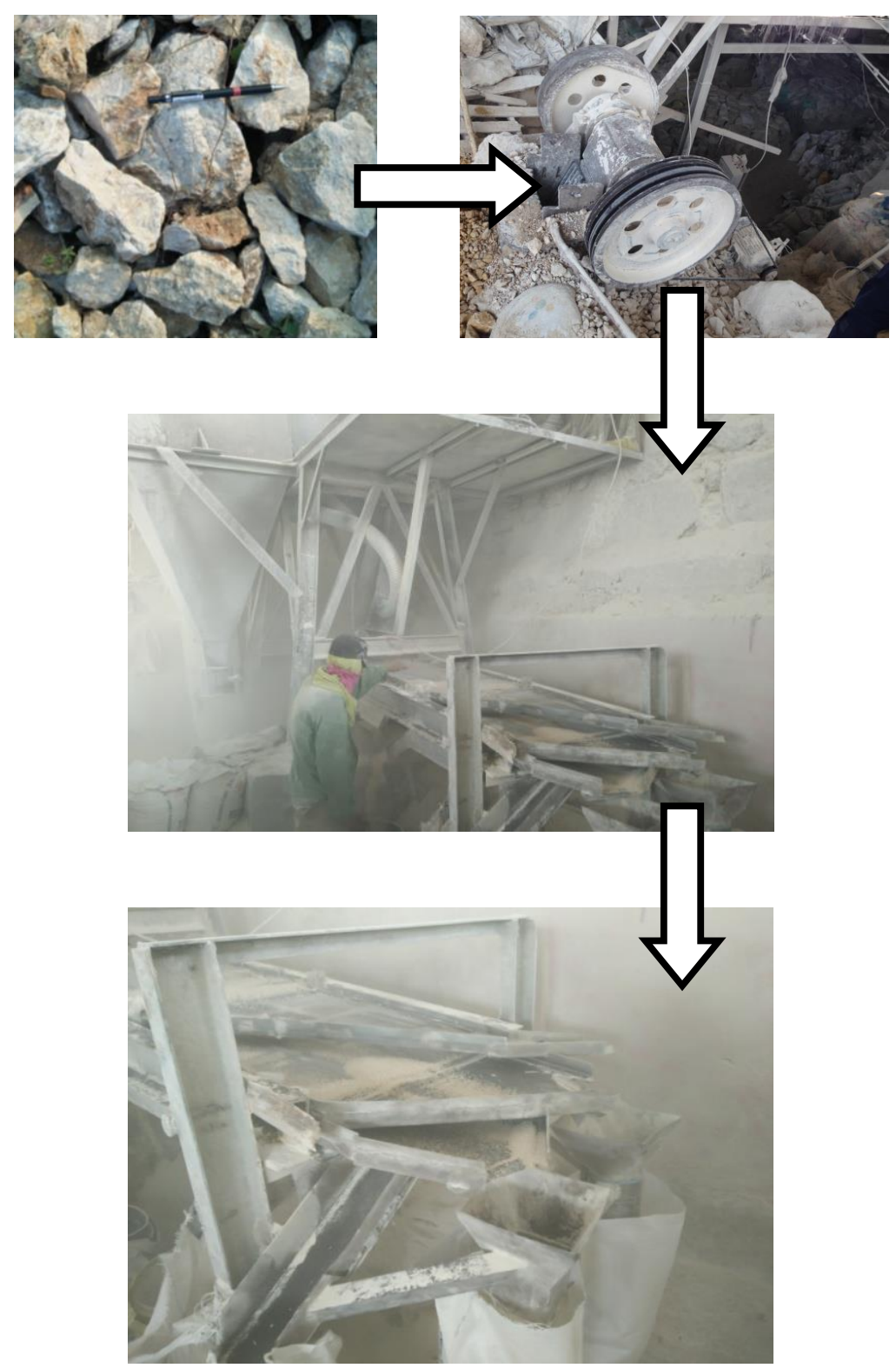

Gambar 3. Proses crushing

Setelah melalui proses cruhing di pabrik, selanjutnya sampel uji dimasukan ke dalam karung dengan berat $\pm 50 \mathrm{~kg}$ untuk dibawa ke laboratorium uji seperti tampak pada Gambar 3. 


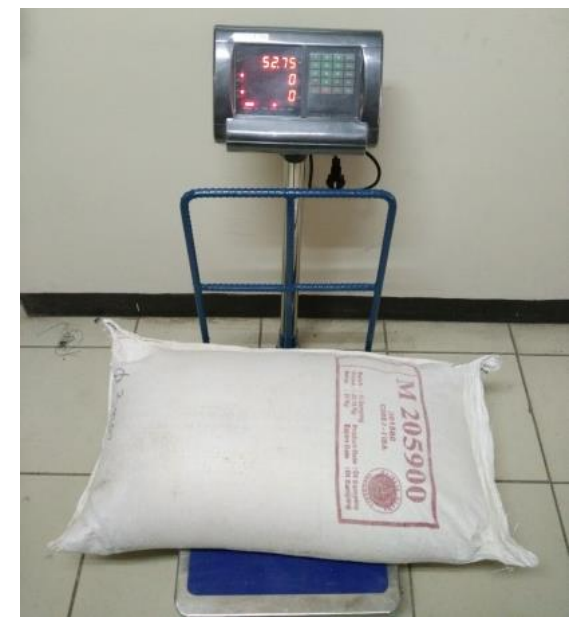

\section{Gambar 3. Sampel Uji Material Crushed Limestone Saat Tiba di Laboratorium}

Setalah tiba di laboratorium, material uji melewati proses quartering untuk mendapatkan sampel uji yang representatif. Proses quartering tampak pada Gambar 4.

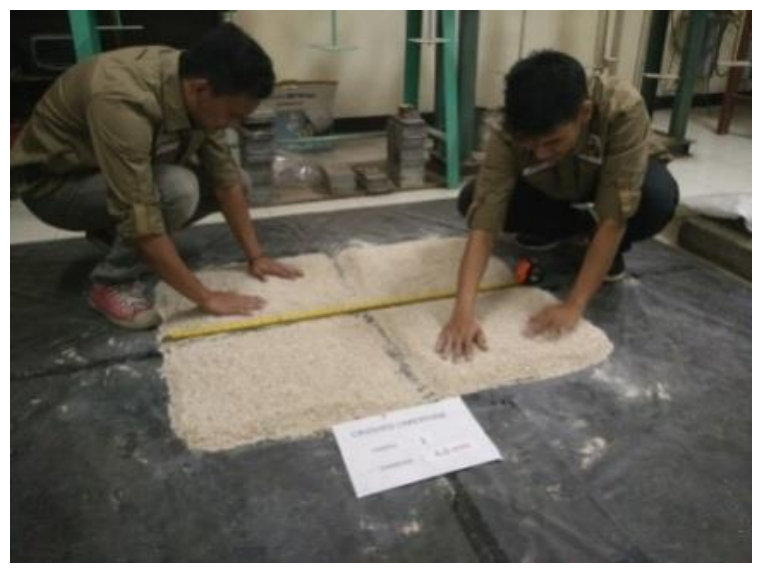

(a)

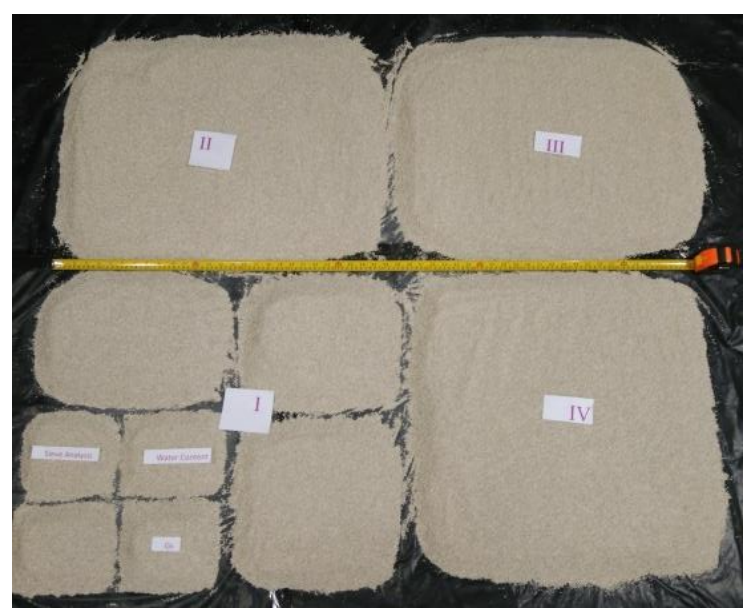

(b)

Gambar 4. (a) Proses Quartering (b) Sampel Uji Material Crushed Limestone 
Nilai water content dan specific gravity untuk material crushed limestone dinyatakan pada Tabel 1. Kadar air yang dinyatakan pada Tabel 1 adalah pada kondisi inisial (saat sampel uji dikeluarkan dari karung / tahap persiapan sampel uji). Sementara kurva distribusi ukuran butir untuk material uji tampak pada Gambar 5.

Tabel 1. Indeks Properti Sampel Uji Material Crushed Limestone

\begin{tabular}{cc} 
Material Uji & Crushed Limestone \\
\hline Water Content, $\boldsymbol{w}(\%)$ & 0.17 \\
Specific Gravity, $\mathbf{G}_{\mathrm{s}}$ & 2.71 \\
\hline
\end{tabular}

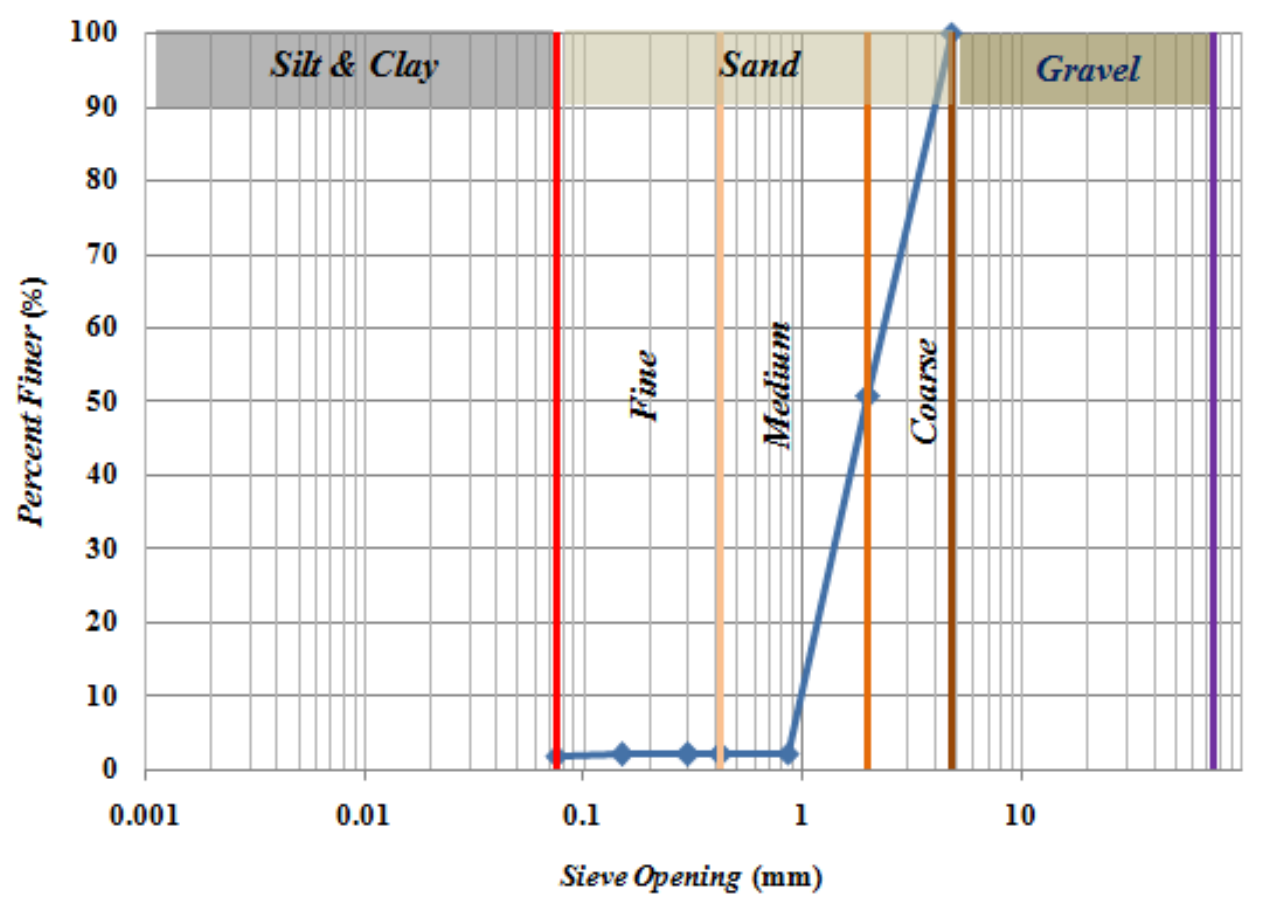

Gambar 5. Kurva Distribusi Ukuran Butir Sample Uji Material Crushed Limestone

Gambar 5 menunjukkan bahwa material crushed limestone yang digunakan sebagai sampel uji adalah didominasi ukuran butir $0.85 \mathrm{~mm}-4.75 \mathrm{~mm}$ sebesar $98 \%$ dan fines content (material yang lolos saringan No.200 [0.075mm]) sebesar $2 \%$.

Nilai coefficient of uniformity (koefisien keseragaman), $\mathrm{C}_{\mathrm{u}}$, dan nilai coefficient of curvature (koefisien gradasi), $\mathrm{C}_{\mathrm{c}}$ ditentukan dengan mengunakan persamaan yang mengacu pada ASTM D 2487, sebagai berikut : 


$$
\begin{aligned}
& C_{u}=\frac{D_{60}}{D_{10}} \\
& C_{c}=\frac{D_{30}{ }^{2}}{D_{60} \cdot D_{10}}
\end{aligned}
$$

dimana:

$$
\begin{aligned}
& D_{10}=\text { diameter yang bersesuaian dengan } 10 \% \text { lolos ayakan (sieve) } \\
& D_{30}=\text { diameter yang bersesuaian dengan } 30 \% \text { lolos ayakan (sieve) } \\
& D_{60}=\text { diameter yang bersesuaian dengan } 60 \% \text { lolos ayakan (sieve) }
\end{aligned}
$$

Nilai $C_{u}, C_{c}$ serta jenis gradasi dari sampel uji dinyatakan pada Tabel 3.

Tabel 3. Parameter $\mathrm{C}_{\mathrm{u}}, \mathrm{C}_{\mathrm{c}}$, \% Fines dan Jenis Gradasi untuk Sampel Uji Material Crushed Limestone

\begin{tabular}{|c|c|c|c|}
\hline Material Uji & $\begin{array}{c}\text { Coefficient of } \\
\text { Uniformity } \\
\left(\mathbf{C}_{\mathbf{u}}\right)\end{array}$ & $\begin{array}{c}\text { Coefficient of } \\
\text { Curvature } \\
\left(\mathbf{C}_{\mathbf{c}}\right)\end{array}$ & Jenis Gradasi \\
\hline $\begin{array}{c}\text { Crushed } \\
\text { Limestone }\end{array}$ & 2.43 & 0.87 & Poorly graded \\
\hline
\end{tabular}

Uji unsur kimia pada material crushed limestone dilakukan dengan metoda XRF. Uji tersebut dilakukan di Laboratorium Pusat Survei Geologi Bandung. Hasil uji unsur kimia dinyatakan pada Tabel 4.

Tabel 4. Hasil Uji Kimia dengan Metoda XRF pada Material Crushed Limestone (Nugraha et al, 2017)

\begin{tabular}{|c|c|c|c|}
\hline Oksida & Satuan & Jumlah & Elemen \\
\hline $\mathrm{SiO}_{2}$ & $\%$ & 0.839 & $\mathrm{Si}$ \\
\hline $\mathrm{TiO}_{2}$ & $\%$ & 0.0155 & $\mathrm{Ti}$ \\
\hline $\mathrm{Al}_{2} \mathrm{O}_{3}$ & $\%$ & 0.268 & $\mathrm{Al}$ \\
\hline $\mathrm{Fe}_{2} \mathrm{O}_{3}$ & $\%$ & 0.232 & $\mathrm{Fe}$ \\
\hline $\mathrm{MnO}$ & $\%$ & 0.0095 & $\mathrm{Mn}$ \\
\hline $\mathrm{CaO}$ & $\%$ & 55.86 & $\mathrm{Ca}$ \\
\hline $\mathrm{MgO}$ & $\%$ & 1.33 & $\mathrm{Mg}$ \\
\hline $\mathrm{Na} 2 \mathrm{O}$ & $\%$ & 0.0878 & $\mathrm{Na}$ \\
\hline $\mathrm{K}_{2} \mathrm{O}$ & $\%$ & 0.0174 & $\mathrm{~K}$ \\
\hline $\mathrm{P}$ & $\%$ & 0.0325 & $\mathrm{P}$ \\
\hline $\mathrm{SO}_{3}$ & $\%$ & 0.015 & $\mathrm{~S}$ \\
\hline
\end{tabular}




\begin{tabular}{|c|c|c|c|}
\hline $\mathrm{SrO}$ & $\%$ & 0.0286 & $\mathrm{Sr}$ \\
\hline $\begin{array}{c}\text { LOI } \\
\text { (Lost of Ignation) }\end{array}$ & $\%$ & 40.36 & - \\
\hline
\end{tabular}

Tabel 4 menunjukkan bahwa menunjukan bahwa oksida yang terbesar adalah $\mathrm{CaO}$, dengan jumlah $55,86 \%$.

\subsection{Energi Kompaksi Di Laboratorium}

Mold (cetakan) dan rammer (penumbuk) standard Proctor (ASTM D 698) yang digunakan untuk keseluruhan uji kompaksi di laboratorium tampak pada Gambar 5.

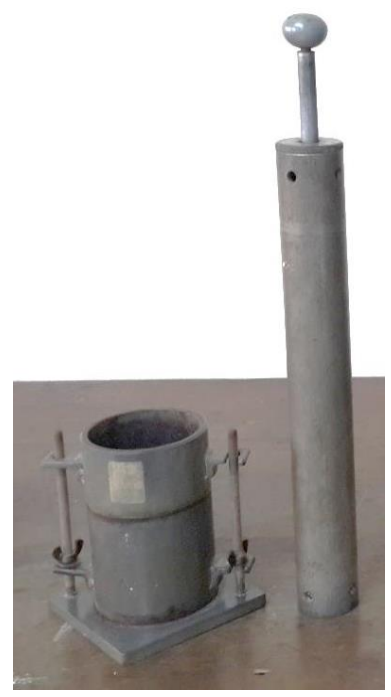

\section{Gambar 5. Mold dan Rammer untuk Uji Standard Proctor}

Energi pemadatan/kompaksi (E) ditentukan dengan menggunakan persamaan berikut :

$$
E=\frac{\text { Berat Rammer } x \text { Tinggi Jatuhx Jumlah Lapis } x \text { JumlahTumbukanper lapis }}{\text { VolumeMold }}
$$

dimana:

$$
\begin{array}{ll}
\text { Berat rammer } & =2.5 \mathrm{~kg} \\
\text { Tinggi jatuh } & =30.5 \mathrm{~cm} \\
\text { Volume mold } & =950 \mathrm{~cm}^{3} \\
\text { Jumlah tumbukan per lapis } & =25 ; 35 ; 56 ; \text { dan } 75 \text { (4 variasi) } \\
\text { Jumlah lapisan } & =3 \text { lapisan (di dalam Mold) dan tetap untuk } \\
& \text { setiap variasi tumbukan }
\end{array}
$$


Penomoran sampel uji dan besar energi yang bersesuaian dengan variasi jumlah tumbukan per lapis tanah pada mold standard Proctor dinyatakan pada Tabel 6.

Tabel 6. Energi Pemadatan untuk Setiap Jumlah Tumbukan per Lapis Tanah Pada Mold-Standard Proctor

\begin{tabular}{|c|c|c|}
\hline $\begin{array}{c}\text { Jumlah Tumbukan } \\
\text { Per Lapis }\end{array}$ & \multicolumn{2}{|c|}{ Energi Pemadatan, E } \\
\cline { 2 - 3 }$\left(\mathbf{k N . m} / \mathbf{m}^{\mathbf{3}}\right)$ & Simbol \\
\hline 25 & 605 & E1 \\
\hline 35 & 847 & E2 \\
\hline 56 & 1356 & E3 \\
\hline 75 & 1816 & E4 \\
\hline
\end{tabular}

\section{HASIL UJI DAN ANALISIS}

Kurva kompaksi yang diperoleh dari hasil uji kompaksi terhadap material crushed limestone dengan energi kompaksi E1 tampak pada Gambar 6. Parameter kompaksi untuk material cruhsed limestone dengan energi kompaksi $605 \mathrm{kN} . \mathrm{m} / \mathrm{m}^{3}$ (energi standard Proctor test) dinyatakan pada Tabel 7.

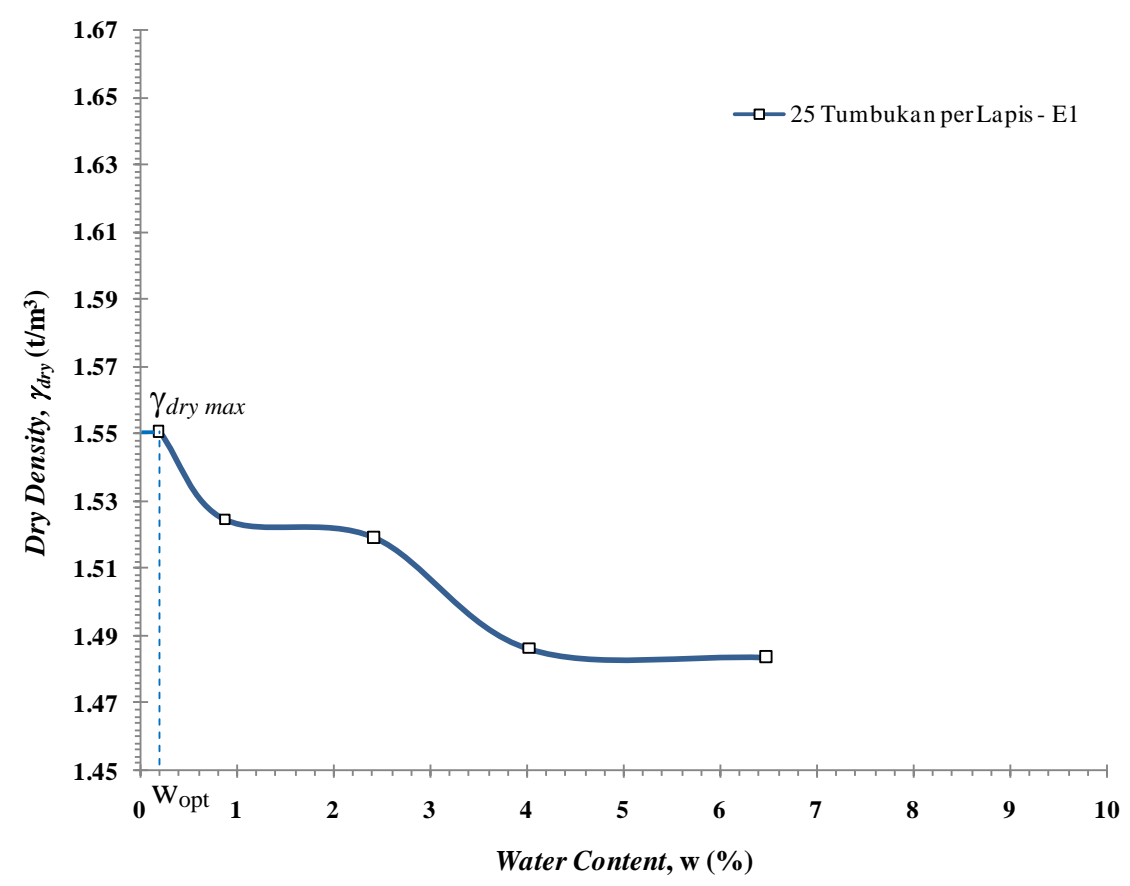

Gambar 6. Kurva Kompaksi untuk 25 Tumbukan per Lapis (Energi, E1 = $\left.605 \mathrm{kN} \cdot \mathrm{m} / \mathrm{m}^{3}\right)$ 
Tabel 7. Parameter Kompaksi untuk Energi = E1 (Energi Standard Proctor)

\begin{tabular}{|c|c|c|c|}
\hline $\begin{array}{c}\text { Jumlah Tumbukan } \\
\text { per Lapis }\end{array}$ & $\begin{array}{c}\text { Energi } \\
\left(\mathbf{k N} \cdot \mathbf{m} / \mathbf{m}^{\mathbf{3}}\right)\end{array}$ & $\begin{array}{c}\mathbf{W}_{\text {opt }} \\
(\mathbf{\%})\end{array}$ & $\begin{array}{c}\gamma_{d r y} \max \\
\left(\mathbf{t} / \mathbf{m}^{\mathbf{3}}\right)\end{array}$ \\
\hline 25 & 605 & 0.2 & 1.55 \\
\hline
\end{tabular}

Perbandingan kurva kompaksi material crushed limestone pada kondisi 35 tumbukan per lapis (E2), 56 tumbukan per lapis (E3) dan 75 tumbukan per lapis (E4) terhadap kurva kompaksi pada kondisi 25 tumbukan per lapis (E1 atau energi standard Proctor test) tampak berturut-turut pada Gambar 7 hingga Gambar 9.

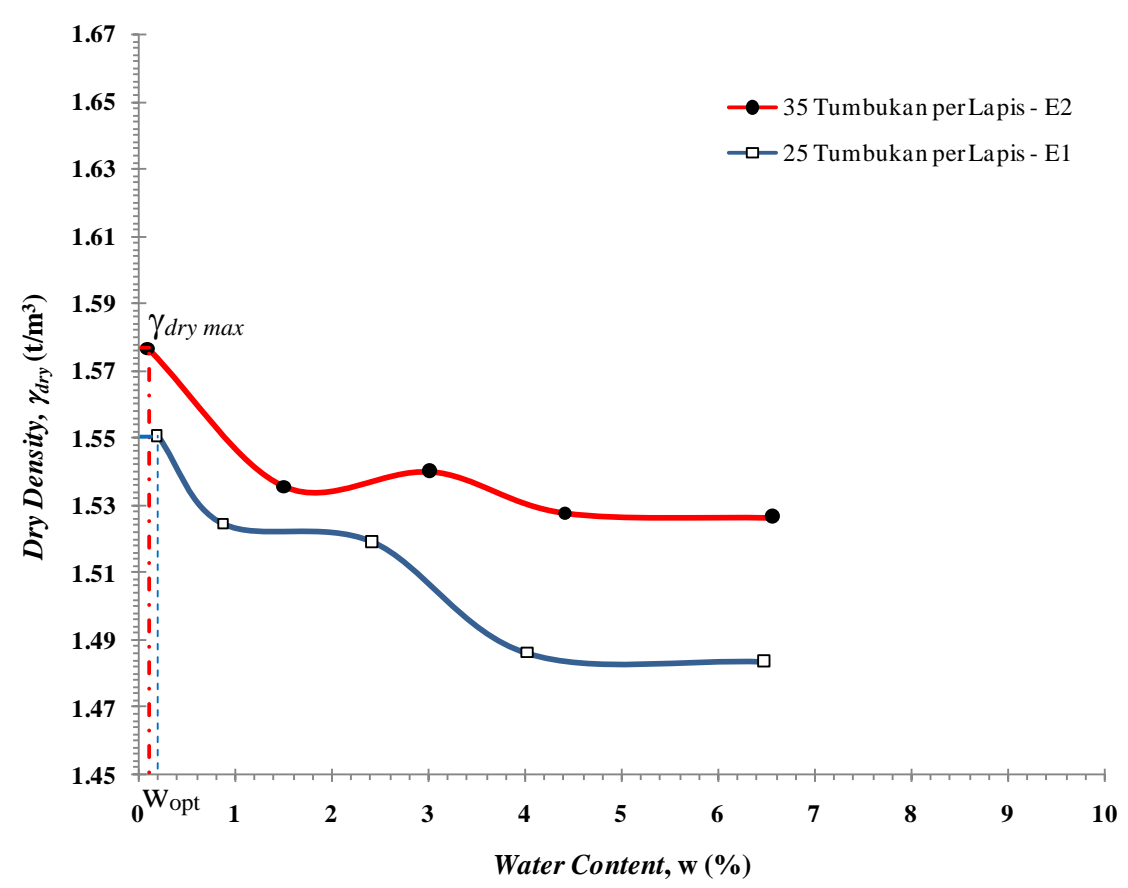

Gambar 7. Perbandingan Kurva Kompaksi E2 Terhadap E1 


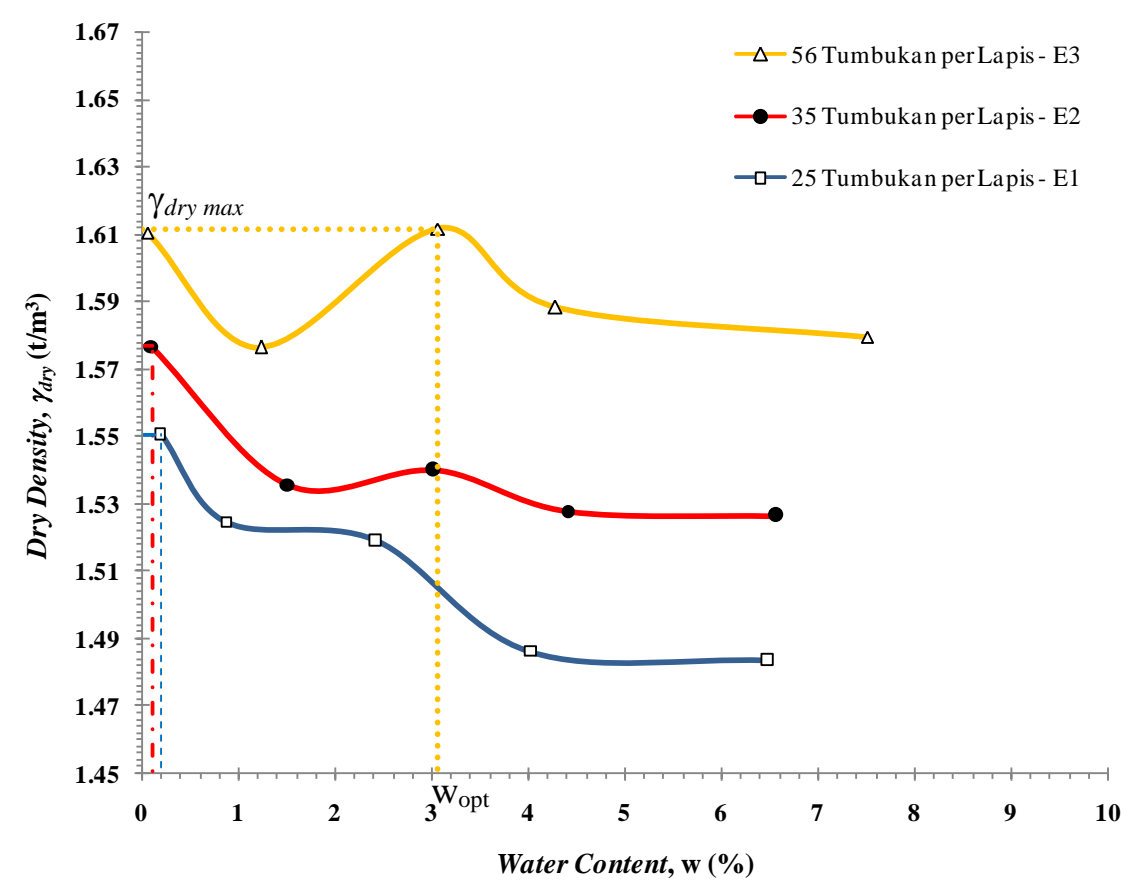

Gambar 8. Perbandingan Kurva Kompaksi E3 dan E2 Terhadap E1

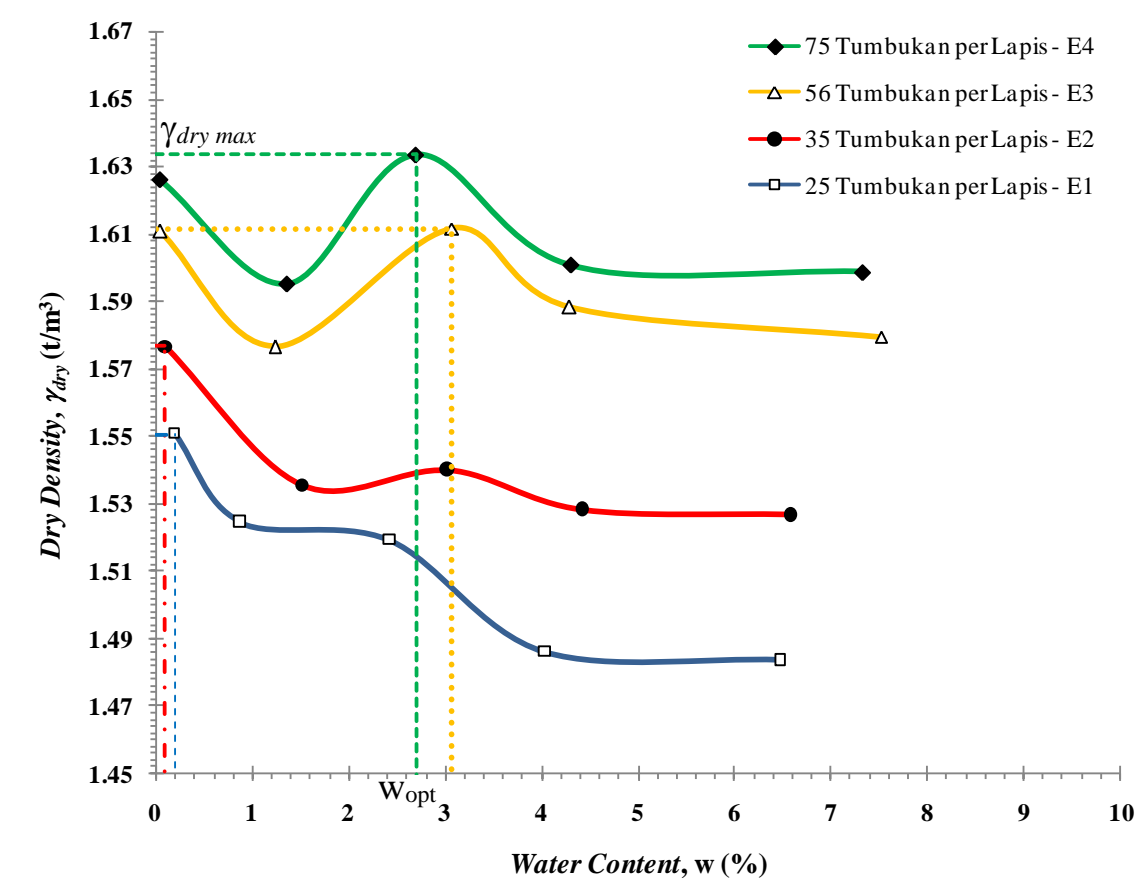

Gambar 9. Perbandingan Kurva Kompaksi E4, E3 dan E2 Terhadap E1

Gambar 9 menunjukkan bahwa terdapat 2 (dua) pola atau trend kurva kompaksi yang dihasilkan. Pola pertama adalah dihasilkan oleh kurva kompaksi dengan energi E1 dan E2, sementara pola kedua dihasilkan oleh kurva kompaksi dengan energi E3 dan E4. 
Pada pola pertama, nilai $\gamma_{\text {dry } \max }$ diperoleh pada kondisi $\mathrm{w}_{\mathrm{opt}}<1 \%$. Sementara pada pola kedua, nilai nilai $\gamma_{d r y \max }$ diperoleh pada kondisi $\mathrm{w}_{\mathrm{opt}}$ mendekati nilai $3 \%$.

Parameter kompaksi yang diperoleh dari setiap kurva kompaksi ( 4 variasi energi) dinyatakan Tabel 7.

Tabel 7. Parameter Kompaksi Material Crushed Limestone untuk Setiap Variasi Energi

\begin{tabular}{|c|c|c|c|c|}
\hline $\begin{array}{c}\text { Jumlah Tumbukan } \\
\text { Per Lapis }\end{array}$ & \multicolumn{2}{|c|}{ Energi Pemadatan } & \multirow{2}{*}{$\begin{array}{c}\mathbf{w}_{\text {opt }} \\
(\mathbf{\%})\end{array}$} & $\begin{array}{c}\gamma_{\text {dry } \max } \\
\left(\mathbf{t} / \mathbf{m}^{\mathbf{3}}\right)\end{array}$ \\
\cline { 2 - 3 } & $\left(\mathbf{k N . m} \mathbf{m}^{\mathbf{3}}\right)$ & Simbol & & \\
\hline 25 & 605 & E1 & 0.2 & 1.55 \\
\hline 35 & 847 & E2 & 0.1 & 1.58 \\
\hline 56 & 1356 & E3 & 3.1 & 1.61 \\
\hline 75 & 1816 & E4 & 2.7 & 1.63 \\
\hline
\end{tabular}

Tabel 7 menunjukkan bahwa pada saat uji kompaksi dengan kondisi energi pemadatan $\mathrm{E} 2, \mathrm{w}_{\mathrm{opt}}$ cenderung berkurang sedikit dari $\mathrm{w}_{\mathrm{opt}}$ yang diperoleh pada saat energi E1, hal ini bersesuaian dengan nilai $\gamma_{\text {dry } \max }$ pada kondisi E2 lebih besar sedikit dari $\gamma_{\text {dry } \max }$ pada kondisi E1 (pola pertama). Demikian pula halnya pada kondisi energi pemadatan E4, $\mathrm{w}_{\mathrm{opt}}$ cenderung berkurang sedikit dari $\mathrm{w}_{\mathrm{opt}}$ yang diperoleh pada saat energi E3, hal ini bersesuaian dengan nilai $\gamma_{d r y} \max$ pada kondisi E4l ebih besar sedikit dari $\gamma_{d r y} \max$ pada kondisi E3 (pola kedua).

Kurva hubungan antara energi pemadatan (E) dan $\gamma_{d r y} \max$ tampak pada Gambar 10. Batasan kurva tersebut adalah untuk rentang nilai $\mathrm{w}_{\mathrm{opt}} \simeq 0.1 \%-3.0 \%$. 


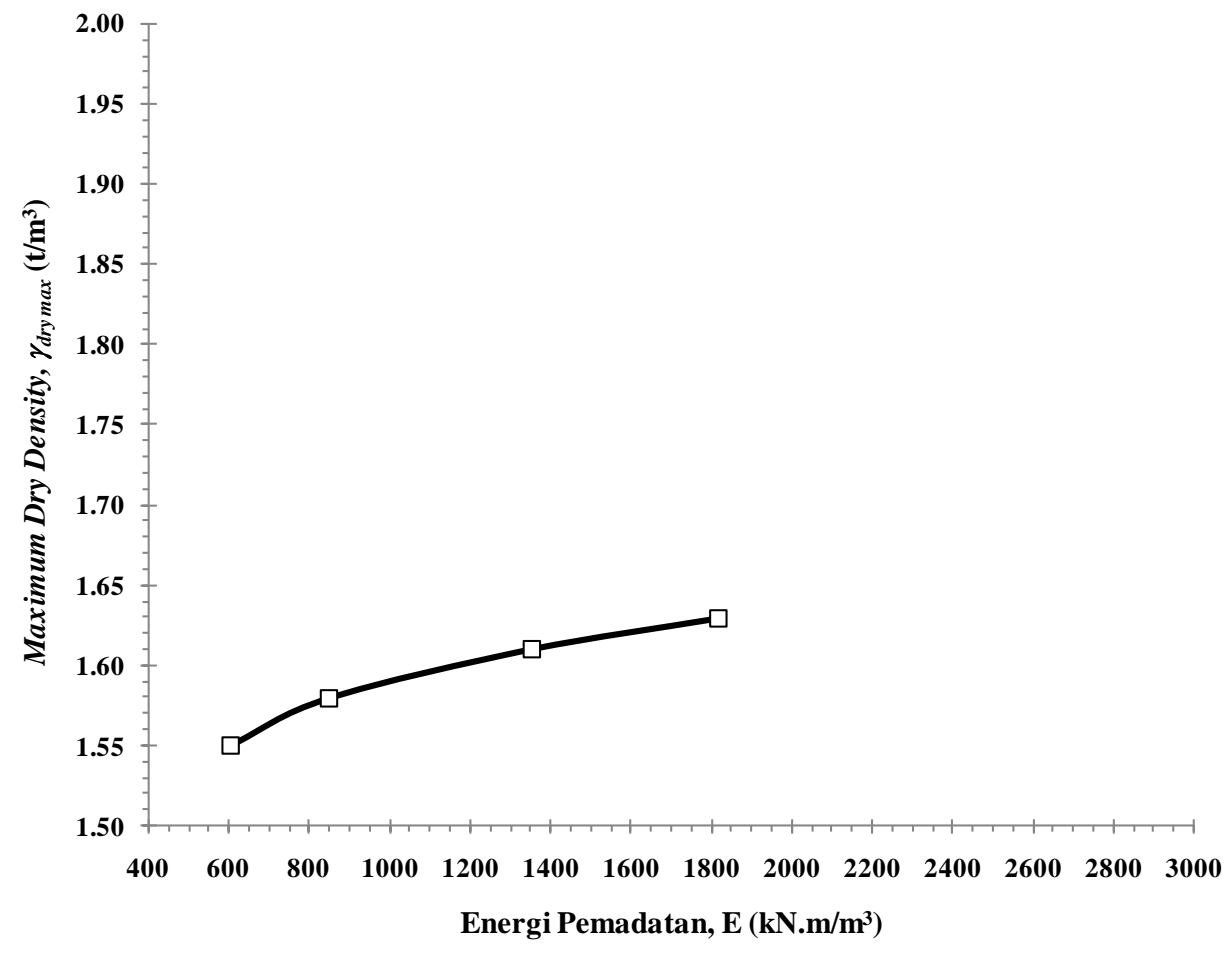

Gambar 10. Kurva Energi Pemadatan - $\gamma_{d r y} \max$

Rasio energi pemadatan, persentase peningkatan $\gamma_{\text {drymax }}$ dan rasio $\gamma_{\text {drymax }}$ terhadap kondisi uji standard Proctor untuk setiap variasi energi pemadatan dinyatakan pada Tabel 8.

Tabel 8. Rasio Energi Pemadatan, Persentase Peningkatan $\gamma_{\text {drymax }}$ dan Rasio $\gamma_{\text {drymax }}$ terhadap kondisi Uji Standard Proctor untuk setiap Variasi Energi

\begin{tabular}{|c|c|c|c|c|c|}
\hline \multicolumn{2}{|c|}{ Energi } & \multirow{2}{*}{$\frac{\text { Energi Pemadatan }}{\text { Energi }(\text { SP) }}$} & \multirow[b]{2}{*}{$\begin{array}{l}\gamma_{d r y \max } \\
\left(\mathrm{t} / \mathbf{m}^{3}\right)\end{array}$} & \multirow{2}{*}{$\begin{array}{c}\text { Peningkatan } \\
\gamma_{\text {dry max }} \\
(\%)\end{array}$} & \multirow{2}{*}{$\frac{\gamma_{d r y \max }}{\gamma_{\text {dry } \max (S P)}}$} \\
\hline$\left(\mathbf{k N} \cdot \mathbf{m} / \mathbf{m}^{3}\right)$ & Simbol & & & & \\
\hline $605^{*}$ & E1 & 1.0 & $1.55^{*}$ & - & 1.00 \\
\hline 847 & E2 & 1.4 & 1.58 & 2 & 1.02 \\
\hline 1356 & E3 & 2.2 & 1.61 & 4 & 1.04 \\
\hline 1816 & E4 & 3.0 & 1.63 & 5 & 1.05 \\
\hline
\end{tabular}

Keterangan : * $=$ SP $=$ Standard Proctor

Tabel 8 menunjukkan bahwa kenaikan energi dari E1 $\left(605 \mathrm{kN} \cdot \mathrm{m} / \mathrm{m}^{3}\right)$ menjadi $3.0 \times$ E1 $\left(\mathrm{E} 4=1816 \mathrm{kN} . \mathrm{m} / \mathrm{m}^{3}\right)$ hanya menaikan $\gamma_{\text {drymax }}$ sebesar $5 \%$.

Rasio energi pemadatan dan rasio $\gamma_{\text {drymax }}$ pada Tabel 7 selanjutnya digunakan untuk penggambaran kurva normalisasi energi (E) pemadatan terhadap energi standard Proctor dan $\gamma_{d r y}$ max terhadap $\gamma_{d r y} \max$ (Standard Proctor) seperti tampak pada Gambar 11. 


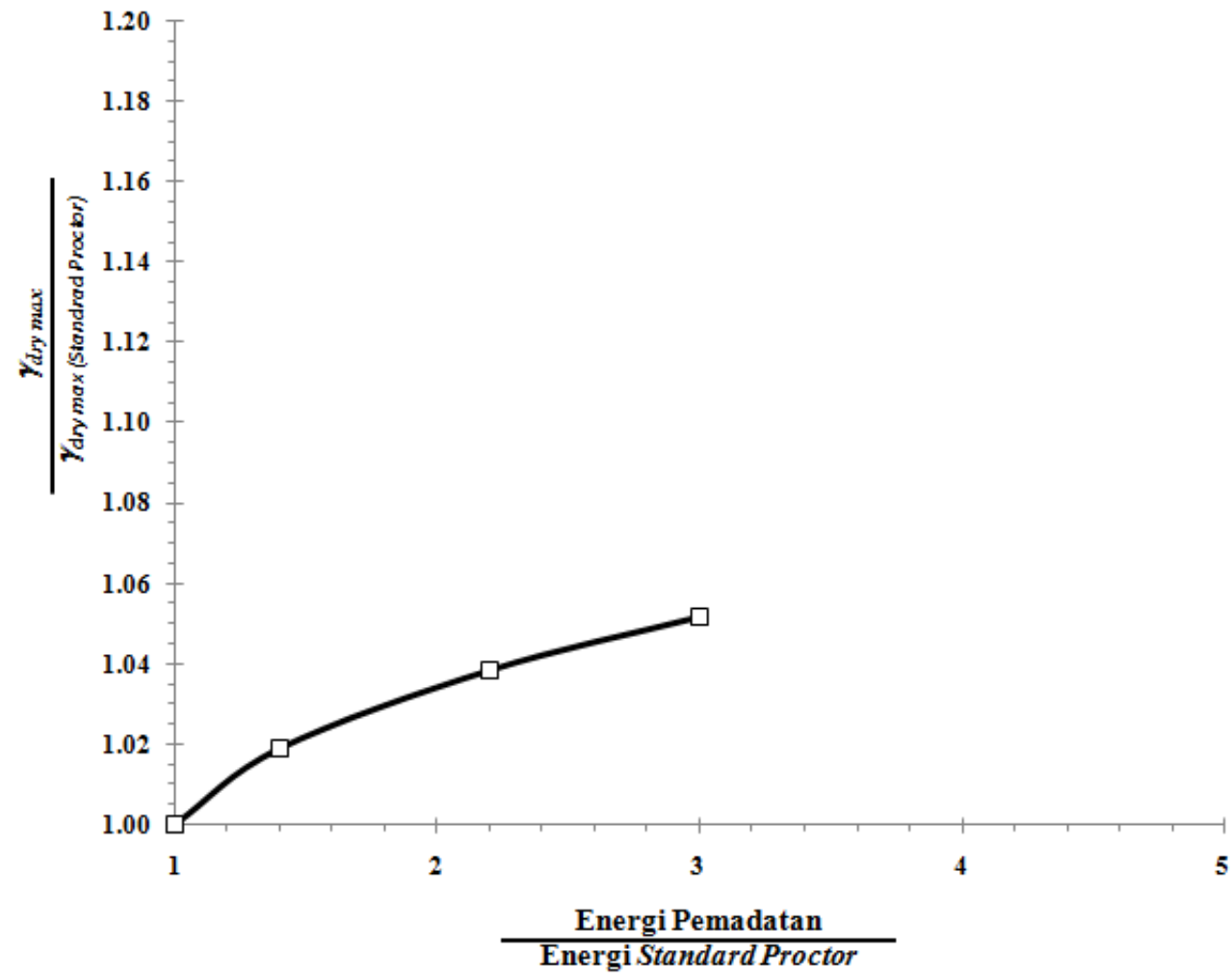

Gambar 11. Kurva Normalisasi $\frac{\text { Energi Pemadatan }}{\text { Energi Standard Proctor }}$ vs $\frac{\gamma_{\text {dry max }}}{\gamma_{\text {dry max (StandardProctor) }}}$

Kurva normalisasi pada Gambar 11 menunjukkan bahwa kurva membentuk suatu kecenderungan untuk menjadi landai (asimtotik) setelah energi pemadatan lebih besar dari 3 kali energi standard Proctor.

\section{SIMPULAN}

Dari hasil studi dapat disimpulkan bahwa peningkatan energi pemadatan untuk kompaksi di laboratorium dari energi standard Proctor sebesar $605 \mathrm{kN} . \mathrm{m} / \mathrm{m}^{3}$ (E1) menjadi $1816 \mathrm{kN} . \mathrm{m} / \mathrm{m}^{3}$ (3xE1) hanya menaikan maximum dry density, $\gamma_{\text {dry } \max }$ sebesar $5 \%$, yaitu dari semula $1.55 \mathrm{t} / \mathrm{m}^{3}$ menjadi $1.63 \mathrm{t} / \mathrm{m}^{3}$. Sementara nilai optimum moisture content, $\mathrm{w}_{\mathrm{opt}}$ berubah dari $0.1 \%$ (kondisi E1) menjadi 2.7\% (kondisi 3xE1).

Hal tersebut menunjukkan bahwa peningkatan energi pemadatan di laboratorium tidak terlalu berpengaruh terhadap nilai $\gamma_{d r y} \max$ maupun $\mathrm{w}_{\mathrm{opt}}$, untuk kondisi crushed 
limestone bergradasi buruk (poorly graded) dan rentang ukuran butir $0.85 \mathrm{~mm}-$ $4.75 \mathrm{~mm}$.

\section{DAFTAR PUSTAKA}

1. ASTM C 136, Standard Test Methods for Sieve Analysis of Fine and Coarse Aggregates, Annual Book of ASTM Standards.

2. ASTM D 2216, Standard Test Methods for Laboratory Determination of Water (Moisture Content) of Soil and Rock by Mass, Annual Book of ASTM Standards.

3. ASTM D 2487, Standard Practice for Classification of soils for Engineering Purposes (Unified Soil Classificication System), Annual Book of ASTM Standards.

4. ASTM D 698, Standard Test Methods for Laboratory Compaction Characteristics of Soil Using Standard Effort, Annual Book of ASTM Standards.

5. $\quad$ BS 1377, (1990), Method of Test for Soils for Civil Engineering Purposes-Part 2: Classification Tests, BSI.

6. Gurtug, Y., and Sridharan, A., (2015), "Prediction of Compaction Behaviour of Soils at Different Energy Levels", International Journal of Engineering Research and Development, Vol.7, No.3.

7. Nugraha, A.S., Fahlevi, J.D., Soentpiet, S.H., (2017), Studi Pengaruh Ukuran Butir terhadap Parameter Kompaksi dan Nilai CBR Material Crushed Limestone Padalarang, Jurnal Teknik Sipil Vol. 13 No. 2, pp. 160 - 179.

8. Satyanarayana, P.V.V., Teja, R.P., Harshanandan, T., Chandra, K.L, (2013), “A Study On The Use Of Crushed Stone Aggregate And Crusher Dust Mixes In Flexible Pavements", International Journal of Scientific \& Engineering Research, Volume 4, Issue 11, November-2013 1126 ISSN 2229-5518, pp 1126 - 1136.

9. Waltham, T., (2009), Foundation of Engineering Geology, $3^{\text {rd }}$ Ed., Spon Press, London.

10. XP CEN ISO/TS 17892-3, (2005), Laboratory Testing of Soil-Part 3: Determination of Particle Density - Pycnometer Method, French Standardizaation, Geotechnical Investigation and Testing.

11. Yong-Jin Choi, Donghyun Ahn, Tan Hung Nguyen and Jaehun Ahn, (2018), "Assessment of Field Compaction of Aggregate Base Materials for Permeable Pavements Based on Plate Load Tests", Sustainability 2018, 10, 3817; doi:10.3390/su10103817. 